\title{
Incidence of primary spontaneous pneumothorax is not associated with microclimatic variations. Results of a seven-year survey in a temperate climate area
}

\author{
Ivan Comelli1, Alessandra Bologna2, Andrea Ticinesi2, Andrea Magnacavallo3, \\ Denis Comelli4, Tiziana Meschi2, Gianfranco Cervellin'
}

\author{
1 Emergency Department, Academic Hospital of Parma \\ 2 Postgraduate Emergency Medicine School, University of Parma \\ 3 Emergency Department, Hospital of Piacenza \\ 4 National Institute of Nuclear Physics, University of Ferrara, Italy
}

\begin{abstract}
Some diseases, such as renal colic and atrial fibrillation, display an association with microclimatic variations. In particular, despite a correlation has been reported between incidence of primary spontaneous pneumothorax (PSP) and meteorological variations, the evidence remains poor and conflictual. The aim of this study was to assess the influence of day-by-day meteorological variations on the number of visits for PSP in the Emergency Department (ED). All PSP cases were retrieved from the hospital database from January 2008 to December 2014. For all the observational days, meteorological data about the Parma Province were obtained from the Environment and Climate Regional Agency. The correlation between ED visits for PSP and variation of air temperature $\left(\mathrm{T}^{\circ}\right)$, atmospheric pressure $(\mathrm{hPa})$ and humidity (\%) was then tested. The chronological data of all the visits for PSP were correlated with climate data by univariate linear regressions analysis. A total number of $608.215 \mathrm{ED}$ visits were recorded during the observational period, with an average of 238 patients per day. Overall, 257 PSP cases were observed (mean age $37 \pm 21$ years), $79 \%$ males and $21 \%$ females. No significant correlation between average daily visits for PSP and daily change of average temperature, humidity, or atmospheric pressure was observed throughout the observational period ( $p>0.05$ for all). The results of the study show that the incidence of PSP is not significantly associated with changes of microclimatic variables.
\end{abstract}

Corresponding author: Gianfranco Cervellin, Emergency Department, Academic Hospital of Parma, Via Gramsci 14, 43126 Parma, Italy.

Tel. +39.0521.703800 - Fax +39.0521.703144. E-mail: gcervellin@ao.pr.it

Key words: Pneumothorax; pressure; temperature; humidity; climate; weather.

Received for publication: 14 November 2016

Accepted for publication: 31 January 2017

(C) Copyright I. Comelli et al., 2017

Tipografia PI-ME Editrice, Italy

Monaldi Archives for Chest Disease 2017; 87:793

doi: 10.4081/monaldi.2017.793

This article is distributed under the terms of the Creative Commons Attribution Noncommercial License (by-nc 4.0) which permits any noncommercial use, distribution, and reproduction in any medium, provided the original author(s) and source are credited.

\section{Introduction}

The term 'pneumothorax', which refers to the presence of air in the pleural 'virtual' cavity (i.e., between the lung and the chest wall), was first proposed by Itard and Laennec in 1803 and 1819, respectively [1]. Although the vast majority of pneumothorax cases were secondary to tuberculosis in the century of Itard and Laennec, some were still identified in apparently healthy subjects (defined as 'pneumothorax simple'). Approximately one century afterward, in 1932, the first description of pneumothorax occurring in healthy subjects (primary spontaneous pneumothorax, PSP) was published by Kjærgaard [2]. Pneumothorax is currently classified as: i) spontaneous (i.e., not caused by trauma or any obvious precipitating factor); ii) traumatic (secondary to both penetrating and blunt chest trauma); and iii) iatrogenic (i.e., secondary to medical procedures or surgical interventions) [3,4]. Spontaneous pneumothorax (SP) is further subdivided in: i) primary spontaneous pneumothorax (PSP), occurring in subjects without clinically apparent lung disease; and ii) secondary spontaneous pneumothorax (SSP), when representing a complication of a preexisting lung disease. Traumatic and iatrogenic pneumothoraces are beyond the topic of this article.

Albeit the precise epidemiology of SP is still not completely known, pneumothorax represents indeed a rather frequent condition, engaging emergency physicians (EPs), intensivists, pulmonologists, general and thoracic surgeons. Epidemiologic data are mainly based on a small number of studies, which seemingly show an incidence of 18$28 / 100.000$ cases yearly in men and $1.2-6 / 100.000$ cases yearly in women, respectively $[5,6]$. No other large-scale studies are available to date, so that a significant part of the epidemiologic knowledge is derived from case series, often showing contradictory figures [7-10]. Regardless of the still partially undefined epidemiology, SP apparently displays a bimodal peak frequency. A first peak typically occurs in the third decade in men (i.e., PSP in tall, thin men), whereas the second peak is observed in both genders starting from the sixth decade, as a consequence of increasing prevalence of chronic lung diseases (mainly chronic obstructive pulmonary disease [COPD]) [6]. Cigarette smoking increases the risk of PSP up to 20 -fold in men, following a dose-dependent fashion $[9,11,12]$.

It is well known that seasonal climate changes are associated with a kaleidoscope of consequences on animal and vegetal biology. Nevertheless, unlike the vast majority of animal species, humans are apparently less affected by seasonal climate changes, since a large part of human life can now be spent in closed environments, where the climate can be 
artificially regulated, and the clothing can be adapted to the actual conditions of temperature and humidity. The health condition may however be influenced by various seasonal changes. Several studies, with different strength of evidence, showed that some associations may exist between meteorological variables and different clinical conditions such as stroke [13], myocardial infarction [14], renal colic [15], atrial fibrillation [16], asthma [17], epistaxis [18], and arthritic pain [19]. Psychiatric emergencies are also influenced by climatic variables, although with variable degrees of strength and evidence [20,21]. It has also been suggested that SP episodes seem to occur in clusters, and in this respect, a correlation between incidence of SP and meteorological variations has been put forward, but the current evidence is scarce and somewhat contradictory [22-24].

Therefore, the aim of this study was to assess the influence of dayby-day meteorological variations on the number of visits for PSP in the local Emergency Department (ED).

\section{Materials and Methods}

All the records of patients visited for SP in the ED of the Academic Hospital of Parma from 1 January 2008 to 31 December 2014 (2555 days) were retrieved from the local hospital database. After thoughtful analysis of all clinical records, the traumatic and iatrogenic pneumothoraces were excluded, along with all cases related to pre-existent pulmonary diseases (i.e., SSPs related to COPD, pneumonia, lung cancer). Overall, 90 cases of SSP were identified and excluded, representing $26 \%$ of all SPs. The Academic Hospital of Parma is a 1150 beds general and teaching hospital, serving a population of about 438.000 inhabitants (ranging from 433.154 in the year 2008, and 445.394 in the year 2014). This hospital is a level 2 Trauma Center and a referral center for stroke and myocardial infarction cases. The ED thus provides acute cardiac and stroke care as well as trauma care. The population of our region is relatively stable, with the only exception of immigration, which is responsible for an average increase of approximately $0.5 \%$ inhabitants per year. Children aged $<14$ years are usually visited in the Paediatric Emergency Room, and data are recorded in a separate database. This study only included adolescent and adult patients (i.e., aged more than 14 years). The meteorological data of the Parma Province were obtained for the Environment and Climate Regional Agency (ARPA; Agenzia Regionale Prevenzione e Ambiente; Environment and Climate Regional Agency, http://www.arpa.emr.it/sim/?osservazioni_e_dati/dexter) of the Region Emilia-Romagna. The site of measurement, located in downtown, was at 10.330313 longitude; 44.808064 north latitude; height $54 \mathrm{~m}$ above sea level. The climate is considered typical of the central-southern Pianura Padana area (also known as 'Po river valley'), and thus continental with $777 \mathrm{mM}$ precipitation per year, peaking in fall and spring. The peak of raining season is in October (averaging $110.2 \mathrm{mM}$ per day), whereas July is the driest month (averaging 37.6 $\mathrm{mM}$ per day). The summer is hot, with peak temperatures ranging between $30-35^{\circ} \mathrm{C}$, whereas the winter is cold, with minimum temperatures rarely below $-20^{\circ} \mathrm{C}$. The mean estimated temperature throughout the study period was $13.5^{\circ} \mathrm{C}\left( \pm 8.6^{\circ} \mathrm{C}\right)$. The number of days with temperature comprised within one standard deviation was 2118 (i.e., 58\%). The mean relative humidity (i.e., the ratio of the partial pressure of water vapour to the equilibrium vapour pressure of water at the same temperature) in this area was $71 \%$ throughout the study period, with a maximum of $100 \%$ and a minimum of $28 \%$. The measurements of air temperature, atmospheric pressure and air humidity were performed on a 1-hour basis, and the mean temperature, atmospheric pressure and humidity of each day was then calculated. The chronological data of all the visits for PSP were associated with climate data by multiple univariate linear regression analysis, using the program Mathematica9 ${ }^{\circledR}$ (Wolfram, Champaign IL, USA). A linear model was then developed, by assumption of independent normally distributed errors, and a formatted analysis of variance table for the model (ANOVA) was finally calculated. The $t$ statistics are the estimates divided by the standard errors. Each p-value is the two-sided p-value for the $t$ statistic and can be used to assess whether the parameter estimate is significantly different from zero. In particular, the following statistics analyses were performed:

- Univariate linear regression analysis between number of visits for PSP and mean daily temperature (Celsius degrees; ${ }^{\circ} \mathrm{C}$ ).

- Univariate linear regression analysis between number of visits for PSP and mean daily humidity (percent; \%).

- Univariate linear regression analysis between number of visits for PSP and mean daily atmospheric pressure (hectopascal; hPa). All the days of observation were included in our analysis, thus comprising also those without episodes of PSP. Due to the retrospective nature of the study and the need to keep anonymous the patients, ethical committee approval was unnecessary. Nevertheless, the study was performed in accordance with the Declaration of Helsinki, under the terms of relevant local legislation.

\section{Results}

A total number of 608,215 ED patient visits were recorded throughout the observational period, with an average of 238 patients per day. Overall, 257 PSP-related visits were recorded during the same period, accounting for 1 PSP case every 9.5 days. Two hundred and three patients, representing $79 \%$ of the whole sample, were men, and 54 patients (i.e., 21\%) were women. The mean age was $37 \pm 21$ years (range 14-94), with two peaks at 25 and 75 years, respectively (Figure 1). The average number of PSPs per day was 0.1 during the observational period, representing $0.04 \%$ of all ED visits. The vast majority of patients was admitted to the ED within 24 hours from onset of the symptoms. Most patients were residents in town or in the immediate neighbourhood (within $20 \mathrm{~km}$ from the weather monitoring station).

The relationship between the average number of PSP and the daily temperature was described by the following formula:

average number of PSP a day $=(0.116+/-0.012)-(0.0010+/-0.0007) \mathrm{T} / C$

$$
(p=0.13 ; R=-0.42)
$$

The relationship between the average number of PSP and the daily humidity was described by the linear fitted formula:

average number of PSP a day $=(0.117+/-0.025)-(0.022+/-0.034) H / \%$

$$
(p=0.5 ; R=-0.19) \text {. }
$$

Finally, the relationship between the average number of PSP and the daily atmospheric pressure was described by the following formula: average number of PSP a day $=(-0.52+/-0.85)+(0.0006+/-0.0008) P / h P a$

$$
(p=0.5 ; R=0.54) \text {. }
$$

As for the previous equations, we failed to find a significant correlation between average daily visits for PSP and daily average temperature ( $\mathrm{p}=0.13$ Figure 2$)$, percentage humidity $(\mathrm{p}=0.5$; Figure 3 ) and atmospheric pressure ( $\mathrm{p}=0.5$; Figure 4 ) throughout the observational period.

Overall, 46 out of 257 patients (i.e., 18\%) were visited twice during the study period for the same disease, which should be considered a high level of recidivism. No patients were visited thrice for PSP during the study period. In the local hospital, surgical procedures are usually limited to recidivism rather than performed during the first episode, so that a third recidivism is extremely rare. 


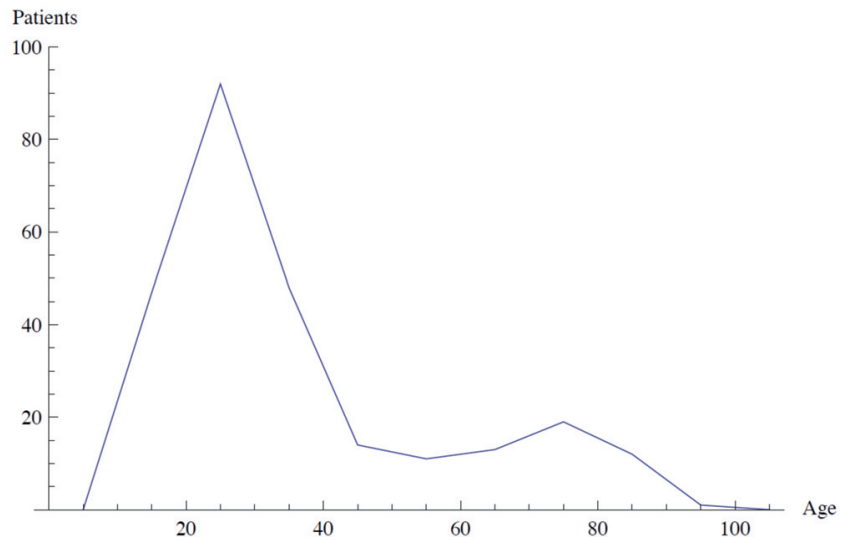

Figure 1. The age distribution of the PSP episodes, showing a double-peak model.

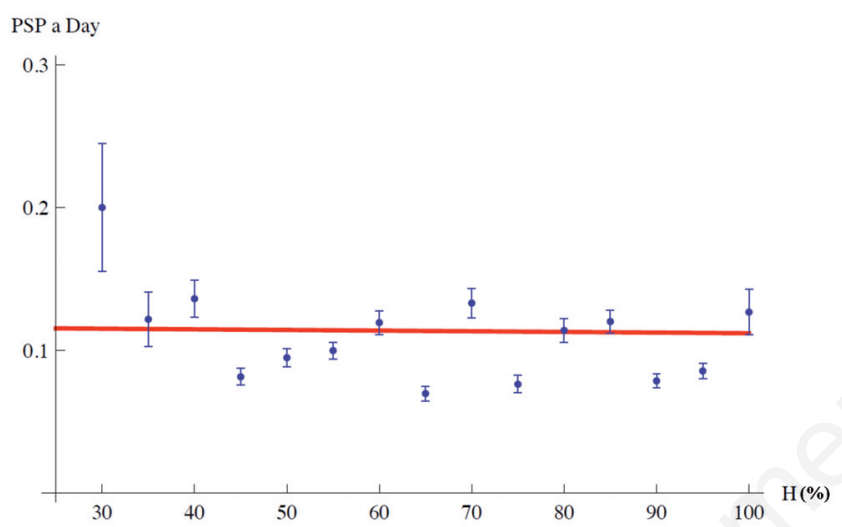

Figure 3. Linear correlation between average number of cases of PSP per day and mean humidity (\%).

\section{Discussion}

This study is one of the largest ever published about the correlation between short-term climate variation and the number of ED visits for PSP to the best of our knowledge. Some preliminary investigations previously described an increased number of ED visits for SP in certain periods of the year, which paved the way to hypothesize the existence of a causal relationship between PSP and seasonality. A universally agreed explanation is lacking, however. Some previous studies described a slight prevalence of SP episodes during springtime [24], peaking during maximum dissemination of pollens [25], as well as during atmospheric increase of nitrogen dioxide $\left(\mathrm{NO}_{2}\right)$ and ozone $\left(\mathrm{O}_{3}\right)$ [26,27]. Nevertheless, additional reports reached different conclusions, showing peaks of SPs during wintertime, in particular from November to February, and linking these findings with an increase in viral upper airways infection $[25,28]$. All the aforementioned evidence has been collected in temperate climate, whereas in subtropical and equatorial areas an increased incidence of SPs has been observed during the hottest months [22,29]. Other studies also showed a uniform distribution of SPs during the year [26,30], occasionally with

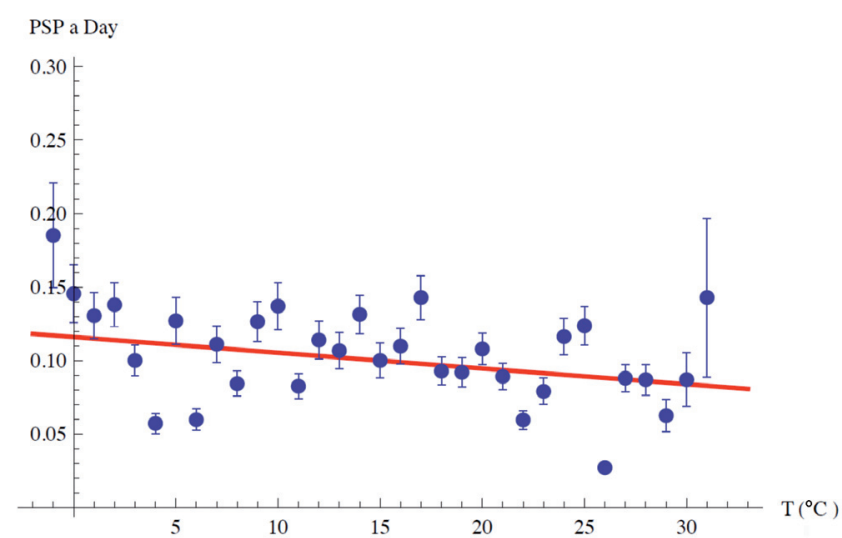

Figure 2. Correlation between average daily visits for PSP and mean air temperature $\left(\mathrm{T}^{\circ} \mathrm{C}\right)$.

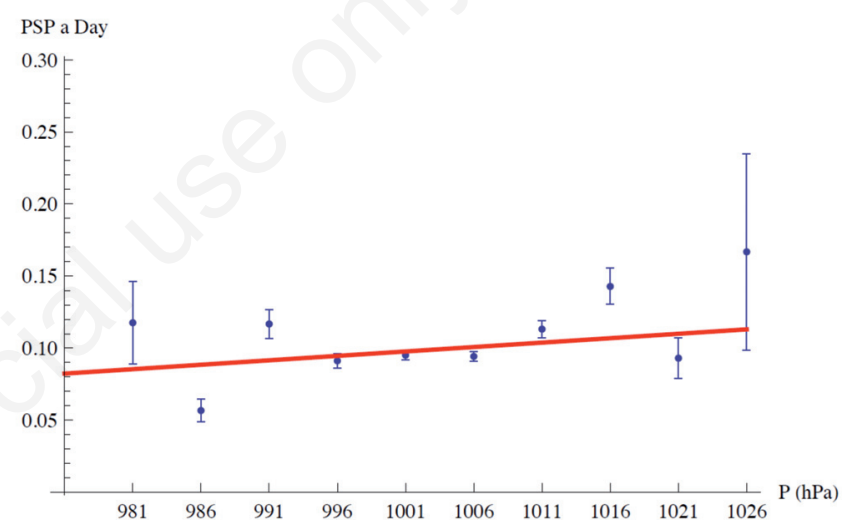

Figure 4. Linear correlation between average number of cases of PSP per day and mean atmospheric pressure $(\mathrm{hPa})$.

slight increase overlapping with sudden climate changes [31-33]. Notably, it has also been hypothesized that small variations in air temperature (as small as $1^{\circ} \mathrm{C}$ ) could be related to the onset of SP, but reliable data in support were lacking [32-34]. Sudden air temperature variations, as in the case of air conditioning during summertime or, contrarily, in the case of heating during wintertime, were not correlated with onset of SP $[31,32,35]$. Atmospheric pressure variations were supposed to act on transpleuric pressure gradient, thus making it easier the breaking of pre-existing blebs, and ultimately leading to development of SP [22,35,37-39]. In particular, some scientists put forward the hypothesis that air pressure variations (e.g., >10 milliBar) could contribute to influence some predisposing conditions of SP [40,41]. Unlike this assumption, only increases of atmospheric pressure were thought to be effective to trigger SP [42]. Finally, some studies did not find any significant correlation between SP and climatic conditions or variations [23,36,43].

Surprisingly, moreover, it seems that 'unusual and extreme' weather conditions, such a typhoon [44], and air travel in cabins constructed with minimum cabin pressurization capability equivalent to $2438 \mathrm{~m}$ $(8000 \mathrm{ft})$ at the maximum operating altitude, as per Federal Aviation Administration (FAA) regulations [45], do not affect PSP occurrence. 
Our study, attempting to find a correlation between PSP incidence and climatic variations in a region with temperate climate, failed to show significant correlations between average daily visits for PSP and three climatic variables (i.e., air temperature, air humidity, and atmospheric pressure). As such, we do not believe that deeper attention to this relationship may help to understand the pathophysiology of the disease. Our results, alongside with several others, suggest that the scientific community should focus on other possible etiological factors for PSP rather than weather modifications. Nevertheless, the results emerged from this investigation confirm the existence of a gender difference, wherein the incidence of PSP was found to be up to 3 -fold higher in men than in women. Another important aspect was the observation of a double-peak model, with a higher incidence of episodes recorded during the third decade and after the seventh decade.

\section{References}

1. Laennec RTH. Traité du diagnostic des maladies des poumons et du coeur. Tome Second, Paris: Brosson and Chaudé, 1819.

2. Kjærgaard H, Anderson H. Spontaneous pneumothorax in the apparently healthy. Copenhagen, Levin \& Munksgaard, 1932: 159 pp.

3. Light RW, Lee RW. Pneumothorax, chylothorax, hemothorax and fibrothorax. In: Murray J, Nadel J, Mason R, et al., eds. Textbook of respiratory diseases. 5th ed. Philadelphia, Saunders Elsevier, 2010: p. 1764-9.

4. Sahn SA, Heffner JE. Spontaneous pneumothorax. N Engl J Med 2000;342:868-74.

5. Melton LJ, Hepper NG, Offord KP. Incidence of spontaneous pneumothorax in Olmsted County, Minnesota: 1950-1974. Am Rev Respir Dis 1979;120:1379-82.

6. Gupta D, Hansell A, Nichols T, et al. Epidemiology of pneumothorax in England. Thorax 2000;55:666-71.

7. Nakamura H, Konishiike J, Sugamura A, et al. Epidemiology of spontaneous pneumothorax in women. Chest 1986;89:378-82.

8. Weissberg D, Refaely Y. Pneumothorax: experience with 1,199 patients. Chest 2000;117:1279-85.

9. Primrose WR. Spontaneous pneumothorax: a retrospective review of aetiology, pathogenesis and management. Scott Med J 1984;29:15-20.

10. Schramel FM, Postmus PE, Vandeschueren RG. Current aspects of spontaneous pneumothorax. Eur Respir J 1997;10:1372-79.

11. Bense L, Eklund G, Wiman LG. Smoking and the increased risk of contracting spontaneous pneumothorax. Chest 1987;92:1009-12.

12. Gobbel WG Jr, Rhea WG Jr, Nelson IA, et al. Spontaneous pneumothorax. J Thorac Cardiovasc Surg 1963;46:331-45.

13. Magalhães R, Silva MC, Correia M, et al. Are stroke occurrence and outcome related to weather parameters? Results from a population-based study in northern Portugal. Cerebrovasc Dis 2011;32: $542-51$

14. Lippi G, Mattiuzzi C, Cervellin G. Seasonal variation in the frequency of myocardial infarction diagnosed in a large emergency department of a European country with a temperate climate. Emerg Care J 2015;11:5450. doi:10.4081/ecj.2015.5450

15. Cervellin G, Comelli I, Comelli D, et al. Mean temperature and humidity variations, along with patient age, predict the number of visits for renal colic in a large urban Emergency Department: results of a 9-year survey. J Epidemiol Glob Health 2012;2:31-8.

16. Comelli I, Ferro J, Lippi G, et al. Incidence of acute-onset atrial fibrillation correlates with air temperature. Results of a nine-year survey. J Epidemiol Glob Health 2014;4:151-7.
17. Beard JD, Beck C, Graham R, et al. Winter temperature inversions and Emergency Department visits for asthma in Salt Lake County, Utah, 2003-2008. Health Perspect 2012;120:1385-90.

18. Comelli I, Vincenti V, Benatti M, et al. Influence of air temperature variations on incidence of Epistaxis. Am J Rhinol Allergy 2015;29:175-81.

19. Redelmeier DA, Tversky A. On the belief that arthritis pain is related to the weather. P Natl Acad Sci USA 1996;93:2895-6.

20. Volpe FM, Tavares A, Del Porto JA. Seasonality of three dimensions of mania: Psychosis, aggression and suicidality. J Affect Disord 2008;108:95-100.

21. Cervellin G, Comelli I, Lippi G, et al. Number of Emergency Department visits for psychiatric emergencies is strongly associated with mean temperature and humidity variations. Results of a nine years survey. Emerg Care J 2014;10:2271. doi:10.4081/ecj.2014.2271

22. Guang-Jian Z, Rui G, Yong Z, et al. Climatic conditions and the onset of primary spontaneous pneumothorax: an investigation of the influence of solar terms. Med Princ Pract 2012;21:345-9.

23. Bulajich B, Gajich M, Kljajich RV, et al. Influence of atmospheric pressure, outdoor temperature, and weather phases on the onset of spontaneous pneumothorax. Ann Epidemiol 2005;15:185-90.

24. Smit HJ, Devillé WL, Schramel FM, et al. Atmospheric pressure changes and outdoor temperature changes in relation to spontaneous pneumothorax. Chest 1999;116:676-81.

25. Accard JL, Patte F, Combes F, et al. Spontaneous pneumothorax. Clinical study, meteorological correlations, course and treatment. Rev Tuberc Pneumonol 1972;36:431-46.

26. Bertolaccini L, Alemanno L, Rocco G, et al. Air pollution, weather variations and primary spontaneous pneumothorax. J Thorac Dis 2010;2:9-15.

27. Abul Y, Karakurt S, Bostanci K, at al. Spontaneus pneumothorax and ozone levels: is there a relation? Multidiscip Resp Mede 2011; 28:16-9.

28. Suarez-Varel MM, Martinez-Selva MI. Llopis-Gonzalez A, et al. Spontaneous pneumothorax related with climatic characteristics in the Valencia area (Spain). Europ J Epidemiol 2000;16:193-198

29. Ayed AK, Bazerbashi S, Ben-Nakhi M, et al. Risk factors of spontaneous pneumothorax in Kuwait. Med Princ Pract 2006;15:338-42.

30. Bertolaccini L, Viti A, Boschetto L, et al. Analysis of spontaneous pneumothorax in the city of Cuneo: environmental correlations with meteorological and air pollutant variables. Surg Today 2015; 45:625-9.

31. Schieman C, Graham A, Gelfand G, et al. Weather and chinook winds in relation to spontaneous pneumothoraces. Can J Surg 2009;52:E151-5.

32. Chen C H, Kou Y R, Chen C S, et al. Seasonal variation in the incidence of spontaneous pneumothorax and its association with climate: A nationwide population-based study. Respirology 2010;15:296-302.

33. Vodicka J, Vejvodová S, Smíd D, et al. Do weather phenomena have any influence on the occurrence of spontaneous pneumothorax? Arch Bronconeumol 2016;52:239-43.

34. Bobbio A, Dechartres A, Bouam S, et al. Epidemiology of spontaneous pneumothorax: gender-related differences. Thorax 2015;70:653-8.

35. Alifano M, Forti Parri SN, Bonfanti B, Arab WA, Passini A, Boaron M, Roche N. Atmospheric pressure influence the risk of pneumothorax: beware of the storm. Chest 2007;131:1877-82.

36. Çelik B, Kefeli Çelik H, Hamzaçebi H, et al. The role of meteorological conditions on the development of spontaneous pneumothorax. Thorac Cardiov Surg 2009;57:409-12.

37. Haga T, Kurihara M, Kataoka $\mathrm{H}$, et al. Influence of weather conditions on the onset of primary spontaneous pneumothorax: positive 
association with decreased atmospheric pressure. Ann Thorac Cardiovasc Surg 2013;19:212-5.

38. Bense L. Spontaneous pneumothorax related to falls in atmospheric pressure. Eur J Respir Dis 1984;65:544-6.

39. Noppen M, Stratakos G, Verbanck S, et al. Fluoresceinenhanced autofluorescence thoracoscopy in primary spontaneous pneumothorax. Am J Respir Crit Care Med 2004;170:680-2.

40. Macquet V, Lafitte P, Rogeaux Y. [Letter: Influence of meteorological conditions on the occurrence of spontaneous pneumothorax]. [Article in French]. Nouv Presse Med 1974;3:1569.

41. Díaz R, Díez MM, Medrano MJ, et al. Influence of atmospheric pressure on the incidence of spontaneous pneumothorax. Cir Esp 2014;92:415-20.
42. Sakai T, Ogura Y, Wakayama F, et al. [Assessment of meteorological conditions in relation to the onset of spontaneous pneumothorax in young adults].[Article in Japanese]. Kyobu Geka 2010; 63:446-8.

43. Heyndrickx M, Le Rochais JP, Icard P, et al. Do atmospheric conditions influence the first episode of primary spontaneous pneumothorax? Interact Cardiovasc Thorac Surg 2015;21: 296-300.

44. Obuchi T, Miyoshi T, Miyahara S, et al. Does pneumothorax occurrence correlate with a change in the weather? Surg Today. 2011; 41:1380-4.

45. Hu X, Cowl CT, Baqir M, et al. Air travel and pneumothorax. Chest 2014;145:688-94. 